\title{
Workers oral health: a cross-sectional study
}

\author{
Marília Jesus Batista', Lílian Berta Rihs², Maria da Luz Rosário de Sousa' ${ }^{1}$ \\ 'Department of Community Dentistry, Piracicaba Dental School, University of Campinas, Piracicaba, SP, Brazil \\ ${ }^{2}$ Municipal Secretary of Health of Piracicaba, Piracicaba, SP, Brazil
}

\begin{abstract}
Adults and elderly usually present an expressive tooth loss in household epidemiologic studies. Few studies were found to report oral health conditions in economically active adults. Aim: To describe the oral health status of adult workers in an extended range age (20-64 years old) of a supermarket chain. Methods: This cross-sectional survey was conducted in a company in the state of São Paulo. A total of 386 workers aged 20 to 64 years old were examined following the guidelines recommended by the World Health Organization (1997) with respect to caries, treatment needs for caries, and need and use of dental prostheses. Age was stratified into groups for analysis. A descriptive analysis was performed and tooth loss rate was calculated. Kruskal Walis and Tukey's tests were used for the evaluation of differences in DMTF and chi-square test was used for treatment needs. Results: The mean DMFT was $14.6( \pm 8.3)$, and differences were found among the 3 groups, mainly due to missing teeth. DMFT was $10.8( \pm 6.95)$ in the 20-34year-old group, $19.6( \pm 6.13)$ in the 35-44-year-old group and $22.1( \pm 7.32)$ in the 45-64-yearold group. Significant differences in tooth loss rate were observed between the age groups (tooth loss rate ranged from $18 \%$ to $81 \%$ ). Among the adults, $53.5 \%$ had treatment needs for caries. Conclusions: The younger adult workers in this study showed better oral conditions and an increase in tooth loss was observed in the older individuals. Considering common risk approach, dentistry should work together with health promotion for the studied population of workers in order to meet the oral treatment needs and prevent new tooth losses.
\end{abstract}

Keywords: adults, occupational health, epidemiology, oral health.

\section{Introduction}

The impact of oral health on daily activities and quality of life is known, as well as the number of working hours lost due to oral diseases ${ }^{1}$ like untreated caries, severe periodontitis and severe tooth loss, which have been listed among the 100 Global Burden Disease in $2010^{2}$. Although the prevalence of caries has been decreasing in the last decades, this health improvement presents significant differences regarding the occurrences of oral diseases among countries, regions,

Received for publication: April 28, 2013 Accepted: July 31, 2013

Correspondence to: Maria da Luz Rosário de Sousa Avenida Limeira, 901, CEP 13414-018

Piracicaba, SP, Brasil

Phone: +551921065209

Fax: +551921065218

E-mail: luzsousa@fop.unicamp.br cities and population groups, like adults ${ }^{1}$. While studies have demonstrated that reduction of oral disease prevalence in household adult population is still a challenge, workers need to be better investigated.

Epidemiological studies among adults focusing on dental caries experience, tooth loss and prosthesis need are useful planning tools for public health. Brazilian nationwide oral health surveys conducted in $1986^{3}, 2003^{4}$ and $2010^{5}$ indicate variations of the caries experience index between adolescents, adults and elderly, chiefly as regards the missing teeth component ${ }^{3}$. While adolescents showed less than one tooth loss, adults from 35 to 44 years of age presented a high number of 
missing teeth in the national epidemiology survey ${ }^{3-5}$. This finding may be explained by oral health actions for adults with priority on immediate dental care and restorative dental procedures $^{6}$. The result of those actions was the predominance of lost teeth (with a $50 \%$ to $90 \%$ variation), as shown by oral health surveys of adults and elderly population in a household sample ${ }^{3}$.

The proportion of economically active adults (older than 20 years) to those who were not working was $2: 1$, in the São Paulo state ${ }^{7}$. Workers are involved with the local productivity and the economically active population, so it is important to know their oral health status focusing dental care and oral health promotion in the working environment. This study is relevant and presents two differentials from the national epidemiological studies carried out at household level: a sample of workers and an extended age range from 20-64 years old. Thus, the objective of the present study was to investigate the oral health status among workers aged 20 to 64 years in a discount supermarket chain.

\section{Material and methods}

\section{Settings and study design}

This cross-sectional study was carried out in São Paulo Metropolitan Region, which consists of 39 municipalities and has 19,889,559 inhabitants ${ }^{7}$. Data were gathered between June 2008 and August 2009 among employees of a discount supermarket chain.

\section{Sample}

The age range of the sample was 20-64 years old, in order extend the WHO age range ${ }^{8}$.

Sample size was determined based on the caries experience variable (DMFT) using data of the Oral Health Epidemiological Survey of the State of São Paulo 9 . In order to calculate the sample size of adults aged 20-29, it was used the DMFT of 19 years old $(8.9 \pm 5.1)$; for adults aged $30-64$ year-old group, it was used the DMFT of 35 to 44 years old $(20.3 \pm 7.61)^{9}$. A $95 \%$ confidence interval was adopted with precision of $20 \%$ and design effect of 2 . It was added $20 \%$ more adults to the sample, in order to compensate losses and refuses, resulting in a sample size of 376 individuals, being 224 for adults in the 20-30 years range and 152 for adults in the 31-64 years range. The company management was previously informed about the research objective and methods. Twenty-five visits were stipulated to the place and random selection of 16 workers among those present at the day of visit, totalizing 400 examined workers to be enrolled. If the adult was absent the day of the visit, a replace was provided. The universe comprised 2000 employees in 2009.

\section{Variables}

Oral examinations were performed at the company site using artificial light, CPI probes and plane dental mirror ${ }^{9}$. The only examiner obtained a $90 \%$ concordant diagnosis compared to the reference regarding the clinical conditions adopted $^{10}$. The intra-examiner agreement was $98.5 \%{ }^{11}$.

DMFT index, treatment needs for caries, need and use of prosthesis were measured following WHO guidelines.

Each volunteer filled in a self-applied questionnaire (61 questions) for verification purposes, like demographic factors and socio-economic factors. The inclusion criteria for the survey were: to belong to one of the established age group categories, to show cognitive abilities to answer a written questionnaire and to agree participating in this research.

\section{Statistical analysis}

Data were tabulated using the Statistical Package for the Social Sciences (SPSS) 17.0 and the Excel. Age was stratified into 3 sub-groups: 20-34, 35-44 and 45-64.

Descriptive analysis was performed. The differences between DMFT and between genders were verified by the Mann Whitney test, those between DMFT (and its components: decayed, missing and filled teeth) and the age groups by the Kruskal Wallis test followed by Tukey's test (post-hoc one-way ANOVA). Statistical differences among treatment needs, age groups and gender were analyzed by the chi-square test. When the $\mathrm{p}$ value was less than 0.05 , it was considered significant.

Because of the great difference in the number of missing teeth, the sample was stratified by age into 9 groups (with 5year intervals) in order to calculate tooth loss rate for each age class, as proposed by Dunning and Klein ${ }^{12}$, using the expression M/DMFT, where the missing teeth component (M) is the dividend and DMFT index the divisor. In order to soften the cumulative effect of dental loss in time, the number of missing teeth in the older age group was removed from the younger subsequent, so that it would be observed which age range presents addition or reduction of tooth losses. Kruskal Wallis test, followed by Tukey's test (post-hoc oneway ANOVA) was applied to compare tooth loss rate among age groups.

\section{Ethical issues}

Considering that human participants were involved in this research, ethical approval was obtained from the Research Ethics Committee of Piracicaba Dental School - State University of Campinas ( $\mathrm{n}^{\circ}$. 122/2005).

\section{Results}

Out of the 400 randomly selected workers, 14 refused to participate. Thus, 386 employees between the ages of 2064 were examined. The mean age was 32.65 years. After stratifying the age groups into 3 sub-groups, there was a predominance of $62.4 \%(n=241)$ of younger adults with ages ranging from 20-34 years, followed by adults from 35 to 44 years old with $24.4 \%(n=94)$ and the oldest $(13.2 \%, n=51)$.

Regarding the evaluated demographic factors, 211 $(54.7 \%)$ were women and the majority $(61.1 \%)$ was born in the city of São Paulo. Workers' mean family income was U\$715.00. Considering the education level, $18.9 \%(n=73)$ completed the elementary school, 71\% $(n=274)$ started or 
Table 1. Mean values of decayed, missing and filled teeth components, DMFT and sound teeth in workers according to age groups in São Paulo, 2009.

\begin{tabular}{|c|c|c|c|c|c|c|}
\hline Age group(years) & $\mathrm{n}(\%)$ & Decayed & Missing & Filled & DMFT & Sound teeth \\
\hline $20-34$ & $241(62.4)$ & $1.32^{\mathrm{a}}( \pm 2.08)$ & $2.35^{\mathrm{a}}( \pm 2.79)$ & $6.84^{\mathrm{a}}( \pm 5.51)$ & $10.79^{\mathrm{a}}( \pm 6.95)$ & 21.21 \\
\hline $35-44$ & $94(24.4)$ & $1.32^{\mathrm{a}}( \pm 1.91)$ & $9.36^{b}( \pm 7.18)$ & $8.46^{\mathrm{a}}( \pm 6.36)$ & $19.58^{b}( \pm 6.13)$ & 12.42 \\
\hline $45-64$ & $51(13.2)$ & $0.61^{\mathrm{a}}( \pm 0.96)$ & $13.45^{c}( \pm 10.12)^{*}$ & $8.38^{\mathrm{a}}( \pm 6.40)$ & $22.10^{b}( \pm 7.32)^{\star *}$ & 9.9 \\
\hline Total & $386(100)$ & $1.23( \pm 1.94)$ & $5.38( \pm 6.88)$ & $7.44( \pm 5.88)$ & $14.56( \pm 8.31)$ & 17.44 \\
\hline
\end{tabular}

Note: The Tukey test was used considering $p<0.05$ for statistical differences. ${ }^{*} p<0.05{ }^{* *} p<0.01$

completed the second grade.

The DMFT mean of the general sample was 14.6. By evaluating each component, decayed teeth were $9.5 \%$ of the index, missing teeth were $38 \%$ and filled teeth $52.5 \%$. No difference was found with respect to the components among the sub-groups, with exception for the $M$ component $(\mathrm{p}<0.05)$. Regarding the DMFT index, a difference was observed in the youngest age group (Table 1). The mean of present teeth was 26.6.

A variation in the mean values of missing teeth among the nine age groups was observed (Table 2). The dental loss rate was higher in the last examined group $(81 \%$, between 60-64 years). An increase in tooth loss rate was perceived till the 45 year-old group, and moreover till those aged 5560 years. The biggest difference in missing teeth could be seen between the 30-35-year-old and the 35-39-year-old groups (4.6) (Table 2).

Although the mean values of decayed teeth $(1.23 \pm 1.94)$ were found not so high in comparison to the other components of the DMFT index, $44.4 \%$ of the studied population presented active caries. Among the examined individuals $53.5 \%$ had some treatment needs (Table 3). Extraction was the only treatment need that showed significant difference in the statistical tests among the 3 sub-groups $(p<0.01)$.

Regarding the use of prosthesis, it was found a greater use of maxillary rather than mandibular prostheses. Divergent values were found comparing the gathered data related to the use of prosthesis among the different age groups (Table 4).

In the evaluation of prosthesis need it was verified that the most prevalent necessity was for fixed prostheses for the substitution of one tooth $(11.1 \%)$. The need for mandibular prostheses was greater compared with maxillary prostheses, and $47.4 \%$ did not need mandibular prostheses (Table 5).

\section{Discussion}

This paper highlights the economically active adult population's oral health data, aged from 20 to 64, which is an extended age range in relation to the WHO recommendations ${ }^{8}$, and requires wider investigation. There are few studies about oral health in the working population and the impact of oral disease is well established on the quality of life and daily activities, like work and study.

The DMFT index varied from 10.80 among the workers aged 20-34 to 19.58 among those aged 35-44 years, in other words an almost $100 \%$ increase. Between the adults in the last group and those in the 45-64-age-group $(\mathrm{DMFT}=22.0)$ there was no significant difference. However, analyzing only the missing teeth component, differences were observed among the three age groups, with variations from 2.3 to 9.4 and 13.5. In British adults as also in the present study, the youngest presented more sound teeth and less restored teeth, representing healthier teeth than the oldest ${ }^{13}$. Therefore, it is important to investigate the DMFT index and its components in different age groups, in order to allow interpretation of the real meaning of this index, which evaluates the caries experience.

In the latest Brazilian nationwide oral health survey $\left(2011^{5}\right)$, the adult population (35-44 years) showed DMFT of 16.3. That means a better result compared with 2003 data,

Table 2. Mean values of missing teeth, tooth loss rate, difference in the mean values of missing teeth among age groups (5-year intervals) in São Paulo, 2009.

\begin{tabular}{lcc|cc}
\hline Age (years) & $\mathrm{n} \%$ & Mean (SD) & $\begin{array}{c}\text { Tooth loss rate } \\
\text { M/DMFT }\end{array}$ & $\begin{array}{c}\text { Differences in tooth loss } \\
\text { among the age groups }\end{array}$ \\
60 to 64 & $4(1.0)$ & $24.75(13.84)^{\mathrm{c}}$ & 0.81 & 11.04 \\
55 to 59 & $8(2.1)$ & $13.71(11.15)^{\mathrm{b}}$ & 0.65 & 2.93 \\
50 to 54 & $9(2.3)$ & $10.78(9.10)^{\mathrm{b}}$ & 0.49 & -1.81 \\
45 to 49 & $30(7.8)$ & $12.59(9.07)^{\mathrm{b}}$ & 0.51 & 1.79 \\
40 to 44 & $45(11.7)$ & $10.98(8.44)^{\mathrm{b}}$ & 0.54 & 3.09 \\
35 to 39 & $49(12.7)$ & $7.89(5.51)^{\mathrm{b}}$ & 0.41 & 4.6 \\
30 to 34 & $58(15.0)$ & $3.29(2.90)^{\mathrm{a}}$ & 0.22 & 0.53 \\
25 to 29 & $94(24.4)$ & $2.76(3.19)^{\mathrm{a}}$ & 0.24 & 1.46 \\
20 to 24 & $89(23.1)$ & $1.30(1.80)^{\mathrm{a}}$ & 0.18 & \\
\hline
\end{tabular}

Note: Different letters indicate significant differences between the groups according to the Tukey's test (post hoc one-way ANOVA) $p<0.01$ 
Table 3. Absolute and percentage distribution of treatment needs among the examined subgroups in São Paulo, 2009.

\begin{tabular}{llllll}
\hline & & $\mathbf{2 0}$ to 34 years & $\mathbf{3 5}$ to 44 years & $\mathbf{4 5}$ to 64 years & $\begin{array}{l}\text { Total } \\
\mathbf{n}(\%)\end{array}$ \\
Treatment needs for caries & No & $112(46.5)$ & $43(45.7)$ & $25(49)$ & $180(46.6)$ \\
& Yes & $129(53.5)^{\mathrm{a}}$ & $51(54.3)^{\mathrm{a}}$ & $26(51)^{\mathrm{a}}$ & $206(53.4)$ \\
Type of needs & Restoration of 1 face & $60(24.9)^{\mathrm{a}}$ & $25(26.9)^{\mathrm{a}}$ & $12(23.5)^{\mathrm{a}}$ & $97(25.1)$ \\
& Restoration of 2 face & $59(24.5)^{\mathrm{a}}$ & $26(27.7)^{\mathrm{a}}$ & $15(29.4)^{\mathrm{a}}$ & $100(25.9)$ \\
& Pulp treatment & $44(18.3)^{\mathrm{a}}$ & $16(17.0)^{\mathrm{a}}$ & $8(15.7)^{\mathrm{a}}$ & $68(17.6)$ \\
& Exodontia & $14(5.8)^{\mathrm{a}}$ & $13(13.8)^{\mathrm{b}}$ & $3(5.9)^{\mathrm{c}^{\mathrm{a}}}$ & $30(7.8)$ \\
\hline
\end{tabular}

Note: Chi-square test; $p<0.05$ was applied for rejection of null hypothesis, ${ }^{*} p<0.01$

Table 4. Use of maxillary and mandibular prostheses among adult workers, São Paulo, 2009.

\begin{tabular}{llll|lll}
\hline \multicolumn{3}{l}{ Use of prothesis } & \multicolumn{3}{c}{ Maxillary } & \multicolumn{3}{c}{ Mandibular } \\
& $20-34$ & $35-44$ & $45-64$ & $20-34$ & $35-44$ & $45-64$ \\
& & $\mathrm{n}(\%)$ & & \multicolumn{3}{c}{$\mathrm{n}(\%)$} \\
No use & $229(95)$ & $68(72.3)$ & $29(56.9)$ & $238(98.8)$ & $87(92.6)$ & $41(80.4)$ \\
1 fixed prosthesis & $4(1.7)$ & $3(3.2)$ & $1(2.0)$ & $1(0.4)$ & $1(1.1)$ & $1(2.0)$ \\
1 removable prosthesis $8(3.3)$ & $16(17)$ & $10(19.7)$ & $2(0.8)$ & $4(4.3)$ & $4(7.8)$ & \\
Combination of prostheses & 0 & 0 & $1(2.0)$ & 0 & 0 & $1(2.0)$ \\
\hline Total prostheses & 0 & $7(7.4)$ & $10(19.6)$ & 0 & $2(2.1)$ & $4(7.8)$ \\
\hline
\end{tabular}

Table 5. Maxillary and mandibular prosthesis needs among adult workers, São Paulo, 2009.

\begin{tabular}{|c|c|c|c|c|c|c|}
\hline \multirow[b]{2}{*}{ Prosthesis needs } & \multicolumn{3}{|c|}{ Maxillary } & \multicolumn{3}{|c|}{ Mandibular } \\
\hline & 20-34 & $35-44$ & $45-64$ & 20-34 & $35-44$ & $45-64$ \\
\hline & & $\mathrm{n}(\%)$ & & & $n(\%)$ & \\
\hline No need & $187(77.6)$ & $51(54.3)$ & $30(58.8)$ & $143(59.3)$ & $23(24.5)$ & $17(33.3)$ \\
\hline Prosthesis for 1 tooth & $28(11.6)$ & $10(10.6)$ & $5(9.8)$ & $38(15.8)$ & $8(8.5)$ & $3(5.9)$ \\
\hline Prosthesis for more than 1 tooth & $4(1.7)$ & $4(4.3)$ & $4(7.8)$ & $5(2.1)$ & $9(9.6)$ & $3(5.9)$ \\
\hline Combination of prostheses & $22(9.1)$ & $28(29.8)$ & $11(21.6)$ & $55(22.8)$ & $53(56.4)$ & $26(51)$ \\
\hline Total prostheses & 0 & $1(1.1)$ & $1(2.0)$ & 0 & $1(1.1)$ & $2(3.9)$ \\
\hline
\end{tabular}

which was $20.1^{4}$. An improvement on adult oral health across years was found in other countries like United States, Canada ${ }^{14}$ and also among the British adults ${ }^{13}$. Although the percentage of the missing teeth component was reduced from $50 \%{ }^{4}$ to $44.8 \%$, it was still the most predominant component of the index. Considering the same age range, and the workers of the current study, a higher value of DMFT than in the latest national survey was observed, but lower mean values of decayed teeth. The samples of the national surveys of 2003 and 2010 were drawn from individuals at their homes, whilst the present study examined company workers. Studies have confirmed the impact of work on the health of an individual. Not only is the access of the low-income population restricted and the conventional dental treatment onerous, but dental care is also influenced by individual living conditions ${ }^{1,15}$. Most of the time, the income is the determinant factor in the choice of the individual for a specific kind of treatment and acquisition of an oral health product.

Extending the view to age groups of adolescents, adults and elderly people, it can be observed in the latest Brazilian surveys that there is a considerable difference in the missing teeth component among these groups ${ }^{4}$. Thus, the present study addresses the importance of examining an extended age group that fits in these age intervals. The adolescents examined in the state of São Paulo, presented 0.42 missing teeth, adults showed 11.25 and elderly people $26.21^{4}$. It was observed a greater difference in the mean values of missing teeth between the 60-64 years old and the age ranges of 3034 and 35-39. These data draw the attention to the need of performing more comprehensive epidemiological studies in younger adults in order to make a deeper evaluation of the moment when the teeth losses seem to occur more often.

The increase of tooth loss in the older age groups has been reported in several studies ${ }^{16}$. However, there are no scientific signs that establish a link between the age process and the tooth losses ${ }^{6}$. In the present study, the rate of missing teeth values showed increasing tendency, which varied from $18 \%$ to $81 \%$, showing differences in the mean values of the nine studied age groups. In Brazil, tooth loss is the result of absence of policies that promote the oral health in adults in 
the past ${ }^{5}$ and could be explained in this study by cohort effect ${ }^{17}$. Recently, new policies have been implemented in order to extend the dental services access to other age groups, beyond the students ${ }^{18}$.

Lacerda et al. ${ }^{19}$ examined adult workers in the South of Brazil and the missing teeth presented the biggest percentage of DMFT (54\%). Nevertheless, in the present examination filled teeth were the highest DMFT component in the total sample. Filled teeth could be associated with dental care, but the restorative treatment should take into account the risks and diagnosis methods, to avoid that the patient be driven to a repetitive restoration cycle $^{20}$.

In Lebanon, 401 adults in the age group 35 to 44 years had $27 \%$ of the DMFT (16.3) referred to the decayed teeth component ${ }^{21}$, higher than in the present study. The importance of interpreting the DMFT index is a means of avoiding false conclusions regarding the dental health. The component decayed teeth, depending on the observed need of treatment might be filled or pulled.

The verification of the treatment needs is relevant to plan dental services. The SB Brasil $2003^{4}$ demonstrated that the more prevalent necessities were low complexity needs like the one- or two-face restorations observed in the present work. It is important to point out that the non-attendance of these needs can drive the evolution of the disease to the tooth loss, which showed in the present study a significant difference among the age groups, being higher among the younger adults, and implying an increase of tooth losses in the future. Untreated caries in permanent dentition affects $35 \%$ of the population, being the most prevalent condition at all ages in the Global Burden Disease, which means loss in years of life due to this oral condition ${ }^{2}$.

The effect of tooth loss can be observed by the needs and use of prosthesis. In the present research, $95 \%$ of the subjects aged 20 to 34 years did not use prosthesis. The use of prosthesis itself is a factor that leads the adult to be classified as a patient with a potential caries risk $^{22}$. WHO and other studies emphasized the importance of controlling caries and periodontal disease, based on risk criteria ${ }^{22}$. It is recommended to them get involved in a prevention program in order to guarantee prosthesis maintenance and adaptation, and to avoid the occurrence of oral diseases ${ }^{22}$.

This original study focused on the adult population that is the labor force of society, and an extended age group in relation to WHO criteria, unlike other studies. Some difficulties, like sampling limitation, occurred because it was difficult to enroll workers older than 45 years - which is an important factor in reaching the target sample size - as the majority of volunteers were between 20 and 30 years old. This study is not representative of all the working population. However, it presents important data of a sample usually not studied such as workers as age range, which brings new knowledge for public health dentistry.

World Health Organization established as goal for the global oral health the minimization of the impact of oral diseases on health and psychosocial development by the year 2020, in order to reduce the absenteeism from school and work. Oral health promotion by early diagnosis and control of diseases is one of the tools to reach this target, which will reflect in the reduction of tooth losses ${ }^{23}$. This knowledge may help understanding the importance of dentistry and medicine working together with a common risk approach to reduce oral disease and promote a healthy environment.

The present study observed that among the examined workers, the youngest presented the best oral health conditions, and showed smaller percentages of need and use of prostheses. The majority of the volunteers needed treatment for caries and the most prevalent necessities were for those of low complexity. The implementation of an efficient program for oral health promotion is needed in order to avoid tooth losses among workers of a supermarket chain.

\section{Acknowledgments}

We thank FAPESP for financial support [scholarship for Master Degree number 2007/57547-0, Research Grant number 2008/53309-0]. Special acknowledgement is due to the manager of the supermarket chain Roldão, as well as the company workers who participated in this study.

\section{References}

1. Petersen PE. The World Oral Health Report 2003: continuous improvement of oral health in the 21st century - the approach of the WHO Global Oral Health Programme. Community Dent Oral Epidemiol. 2003; 31 (suppl.1): 3-24.

2. Marcenes W, Kasseabaum NJ, Barnabé E, Flaxman A, Naghavi M, Lopez A, et al. Global Burden of oral conditions in 1990-2010: a systematic analysis. J Dent Res. 2013; 92: 592-7.

3. Ministry of Health of Brazil. Epidemiological Survey of Oral Health: Brazil, Urban Zone (in Portuguese). Brasília: Centro de Documentação do Ministério da Saúde 1988, 137p. (Série C: estudos e projetos, 4).

4. Ministry of Health of Brazil. SB Brasil 2003: Oral Health Conditions in the Brazilian Population 2002/2003: Main results. Brasília: Ministry of Health, 2004.68p.

5. Ministry of Health of Brazil. SB Brasil 2010: Oral Health Conditions in the Brazilian Population 2010/2011: Main results. (in Portuguese) Brasília: Ministério da Saúde, Secretaria de Atenção à Saúde, Departamento de Atenção Básica. Brasília: Ministério da Saúde, 2012. 92 p. (Série C. Projetos, Programas e Relatórios)._2010.pdf.

6. Narvai PC \& Frazão P. Oral Health in Brazil: More than the roof of the mouth (in Portuguese), Rio de Janeiro: Editora Fiocruz, 148 p.

7. Brazilian Institute of Geography and Statistics (IBGE). Accessed in January 11, 2009. Available from www.ibge.gov.br

8. World Health Organization, Oral heath surveys: basic methods. 4th Ed. Geneva: World Health Organization; 1997.

9. São Paulo State Health Department. University of São Paulo. Oral Health Conditions in the State of São Paulo em 2002 (in Portuguese). São Paulo: Oral Health Center - 22. Secretary of Health of State of São Paulo, 80p.

10. World Health Organization. Basic methods. Geneve: World Health Organization; 1987.

11. Frias AC, Antunes JLF, Narvai PC. Precision and validity of epidemiological surveys of oral health: dental caries in the city of São Paulo in 2002 (in Portuguese). Rev Bras Epidemiol. 2004; 7: 144-54.

12. Dunning JM, Klein $\mathrm{H}$. Saving teeth among home office employees of the metropolitan life insurance company. J Am Dent Assoc. 1944; 31:1632-42.

13. White DA, Tsakos G, Pitts NB, Fuller E, Douglas GVA, Murray GG, et al. Adult Dental Health Survey 2009: Common oral health conditions and their impact on the population. Br Dent J. 2012; 213: 567-72. 
14. Elani HW, Harper S, Allison PJ, Bedos C, Kaufman JS. Socio-economic inequalities and oral health in Canada and the United States. J Dent Res. 2012; 91: 865-70.

15. Watt RG. Emerging theories into the social determinants of health: implications for oral health promotion. Community Dent Oral Epidemiol. 2002; 30: 241-7.

16. Silva DD, Rihs LB, Sousa MRL. Factors associated to the maintenance of teeth in adults in the state of São Paulo, Brazil. Reports in Public Health. 2009; 25: 2407-18.

17. Batista MJ, Rihs LB, Sousa MLR. Risk indicators for tooth loss in adult workers. Braz Oral Res. 2012; 26: 390-6.

18. Antunes JLF, Narvai PC. Dental health policies in Brazil and their impact on health inequalities. Rev Saude Publica. 2010, 44: 360-5.

19. Lacerda JT, Simionato EM, Peres KG, Peres MA, Traebert J, Marcenes W. Dental pain as the reason for visiting a dentist in a Brazilian adult population. Rev Saude Publica. 2004; 38:453-8.

20. Elderton RJ. Preventive (Evidence-Based) approach to quality general dental care. Med Princ Pract. 2003; 12(Suppl 1): $12-21$.

21. Doughan B, Kassak K. Oral health status and treatment needs of 35-44year olds adults in Lebanon. Int Dent J. 2000; 50: 395-9.

22. Featherstone JDB, Singh S, Curtis DA. Caries risk assessment and management for the prosthodontic patient. J Prosthod. 2011; 20: 2-9.

23. Hodbell M, Petersen PE, Clarkson J, Johnson N. Global goals for oral health 2020. Int Dent J, 2003; 53: 285-8. 